\title{
DEL ASPECTO A LA MODALIDAD EPISTÉMICA Y LA EVIDENCIALIDAD. EL CASO DE LA CONSTRUCCIÓN TENER ENTENDIDO
}


La perífrasis tener + participio se caracteriza por expresar un sentido aspectual, pero en los contextos donde el verbo nuclear de la perífrasis es entender, esta tiende a rebasar el plano aspectual para adquirir matices modales. De los valores modales epistémicos pueden surgir significados evidenciales, como en Juan tiene entendido que el maestro no va a venir. El objetivo de este artículo se centra en presentar un análisis diacrónico, del siglo XVI al Xx, de las pautas sintácticas y semánticas que posibilitan la evolución del sentido aspectual al modal en la construcción tener entendido. El trabajo describe la dimensión aspectual de la perífrasis tener entendido y su evolución hacia la modalidad epistémica y evidencialidad, lo que ofrece evidencia a favor de ciertas tendencias del cambio gramatical, como la subjetivización, los procesos metafóricos, los procesos de inferencia y la convencionalización. En la ruta evolutiva que va de la aspectualidad hacia la modalidad y evidencialidad existen contextos puente.

Palabras Clave: perífrasis, aspecto, modalidad epistémica, evidencialidad, contextos puente

The periphrasis tener + entendido express an aspectual sense, but in contexts where the nuclear verb of periphrasis is the verb entender, the periphrasis tends to exceed the aspectual level to acquire modal meanings. The epistemic meanings can arise evidential meanings, like in Juan tiene entendido que el maestro no va a venir. The aim of this paper is to present a diachronic analysis (from the sixteenth to the twentieth century) of syntactic and semantic patterns that enable the development of aspectual meaning to modal construction tener entendido. This work describes the aspectual dimension in the periphasis tener entendido and its evolution to the epistemic modality and evidentiality. That offers evidence from some tendencies of the grammatical change, like the subjetivization, the metaphoric process, the inference process and the conventionalization. In the evolutive way from the aspectuality to the modality and evidentiality, there are bridge cotexts.

KEY WORDS: periphrasis, aspect, epistemic modality, evidentiality, bridge contexts 


\title{
DEL ASPECTO A LA MODALIDAD EPISTÉMICA Y LA EVIDENCIALIDAD. EL CASO DE LA CONSTRUCCIÓN TENER ENTENDIDO
}

\author{
Blanca Sanz \\ Universidad Autónoma de Aguascalientes
}

Como es sabido, los verbos auxiliares de las perífrasis aportan significados temporales, aspectuales o modales. El significado temporal de los auxiliares permite localizar los sucesos en relación con el momento en que se habla. Cuando los auxiliares expresan aspecto, se encuentran orientados al tiempo interno de la situación y, a diferencia del significado temporal, el significado aspectual no se refiere al vínculo con el momento del habla. Algunos verbos auxiliares de las perífrasis también suelen indicar modalidad, es decir, expresan una relación entre los hablantes y lo que estos dicen. ${ }^{1}$

\footnotetext{
${ }^{1}$ La modalidad y el modo constituyen dos categorías distintas. Así como el tiempo verbal es una gramaticalización de la referencia temporal, el modo es un gramaticalización de la modalidad, es decir, el modo es la expresión morfológica de la modalidad. Las modalidades son muchas, pero los modos son pocos - indicativo, subjuntivo e imperativo (en español) - y forzosamente ha de haber un uso múltiple de estos modos para expresar las distintas modalidades.
} 
Esta actitud puede ser, por ejemplo, una creencia, una suposición, un deseo o una orden.

La perífrasis tener + participio se caracteriza por expresar un sentido aspectual, pues predica la terminación de un proceso alcanzado, como se ilustra en 1:
(1) a. Juan tiene leída la novela
b. Juan tiene escrita la carta

A pesar de que la perífrasis tener + participio tiene un valor esencialmente aspectual, en los contextos donde el verbo nuclear de la perífrasis es entender, esta tiende a rebasar el plano aspectual para adquirir matices modales, como se observa en 2 :

(2) Tengo entendido que el maestro no va a venir

Como se puede apreciar, tengo entendido, en lugar de predicar la conclusión del proceso de entendimiento, expresa la idea de duda o incertidumbre, por lo que presenta valores modales epistémicos.

De los valores modales epistémicos pueden surgir significados evidenciales, es decir, por medio de la perífrasis se codifica la fuente de información en la que el hablante basa su afirmación. Así, el ejemplo 2 se puede interpretar en el sentido de que la inferencia o lo dicho por otras personas constituyen la evidencia.

La adquisición de estos valores resulta congruente con las tendencias del cambio diacrónico en el ámbito de la modalidad, pues como señala Traugott (2005: 107), en las len- 
guas que tienen un largo historial documentado, se ha observado que las expresiones modales derivan de expresiones no modales. En este caso, los valores modales desplazan a los aspectuales, es decir, observamos que hay una evolución desde el aspecto hacia la modalidad.

El objetivo de este artículo se centra en presentar un análisis diacrónico de las pautas sintácticas y semánticas que posibilitan la evolución del sentido aspectual al modal en la construcción tener entendido. El periodo que analizaremos comprende los siglos XVI al Xx. Los datos provienen del corpus de Mark Davies.

La metodología del trabajo consistió en realizar un rastreo específico de la construcción tener entendido, a fin de establecer con mayor claridad la evolución hacia la modalidad. Para ello, se documentaron todos los ejemplos de dicha construcción existentes dentro del corpus de Mark Davies.

El cuadro 1 muestra el desplazamiento de los significados aspectuales a favor de los modales. Nótese que casi la totalidad de los ejemplos documentados en el xx presentan valores modales. Esta evolución hacia la modalidad se empieza a hacer más evidente a partir del siglo XIX, en donde más de la tercera parte de los ejemplos documentados presenta valores modales. ${ }^{2}$

\footnotetext{
${ }^{2}$ El cambio abrupto a favor de los valores modales en el siglo xx parece estar relacionado con las tradiciones discursivas. Los datos de los siglos anteriores al $\mathrm{xx}$ se presentan en contextos muy cercanos a la oralidad: en los diálogos de los personajes de textos narrativos, textos dramáticos y textos epistolares; estos últimos se caracterizan por ser diálogos (escritos) diferidos (Castillo, 2002). Para el siglo $\mathrm{xx}$, ya se cuenta con datos de la lengua oral, lo cual podría explicar el aumento porcentual tan brusco. De hecho, de los 155 ejemplos documentados del siglo xx, 138 corresponden a la oralidad (89\%).
} 


\section{Cuadro 1}

\begin{tabular}{|l|c|}
\hline \multicolumn{2}{|c|}{ Frecuencia de tener entendido con valor modal } \\
\hline Siglo & Frecuencia \\
\hline XVI & $8 / 291=2.7 \%$ \\
\hline XVII & $2 / 70=2.8 \%$ \\
\hline XVIII & $14 / 74=18.9 \%$ \\
\hline XIX & $58 / 158=36.7 \%$ \\
\hline XX & $154 / 155=99 \%$ \\
\hline
\end{tabular}

Este análisis cuantitativo revela que, en efecto, la perífrasis muestra un proceso evolutivo hacia la modalidad. A lo largo del trabajo, se abordarán los procesos gramaticales involucrados en dicho cambio, como la subjetivización, los procesos metafóricos, los procesos de inferencia y la convencionalización.

En la primera parte del artículo se presenta una caracterización del sentido aspectual de la perífrasis tener + participio, lo cual ulteriormente permitirá apreciar con mayor claridad los contextos en los cuales la perífrasis se despoja del sentido aspectual para adquirir valores modales.

En la segunda sección, se describe el significado aspectual del verbo entender, a fin de poder comprender el significado aspectual de la construcción tener entendido, el cual se analiza en el tercer apartado. A su vez, el análisis de los significados aspectuales permitirá comprender, en la tercera parte del trabajo, los significados modales epistémicos de la construcción tener entendido.

En la cuarta y quinta sección del artículo, se observa cómo a partir del significado epistémico, las construcciones tener entendido adquieren un significado evidencial. 


\section{Dimensión aspectual de la perífrasis tener + participio}

En general, las perífrasis de participio pasado se caracterizan, desde el punto de vista sintáctico-semántico, por expresar "el resultado de un proceso previo o simultáneo a la época designada por el auxiliar (aspecto 'perfectivo-resultativo')" (Yllera, 1999: 52.2). Por ello, este tipo de perífrasis reciben el nombre de resultativas.

Para ilustrar el sentido resultativo de la perífrasis tener + participio, veamos los ejemplos de 3:

(3) a. Juan tiene escrita la carta

b. María tiene preparada la sopa

c. Pedro tiene pagada la renta de este mes

En los ejemplos anteriores se puede observar que, como resultado de un proceso previo, existe un resultado. En 3a, como resultado del proceso de escritura, existe la carta; algo similar ocurre en 3 b, en tanto que como resultado del proceso de preparación, la sopa tiene existencia. Por último, en $3 c$ el proceso de pago trae como consecuencia que la deuda por la renta mensual esté saldada.

Ahora bien, la secuencia tener + participio no siempre conforma una perífrasis. Se trata de los casos donde el verbo tener funciona como el verbo principal de la oración y el participio funge como predicado secundario o complemento predicativo, como ocurre en 4 :

(4) María tiene irritado el estómago 
En esta oración, el sujeto se encuentra seleccionado por el verbo tener, y no por el participio, como en los casos de las perífrasis ilustradas en 3 . El verboide funciona como un predicado secundario porque modifica simultáneamente al verbo principal y al sintagma nominal objeto directo (el estómago). En este caso, la oración predica el estado de irritación del estómago de María, mas no la conclusión de dicho proceso. $^{3}$

El rasgo aspectual característico de las construcciones con tener en contextos de predicación secundaria es el de mantenimiento de un estado. Además de dicho rasgo, en algunos casos, estas construcciones expresan la idea de control del sujeto sobre el estado del objeto directo, como en $5 \mathrm{a}$, o afectación del sujeto por el estado en que se halla el objeto directo, como en 5b (cf. Sanz Martin, 2011):

(5) a. María tiene abiertas las ventanas de su casa

b. María tiene internado a su papá en el hospital

En 5a, se predica que María es la responsable de que las ventanas de la casa permanezcan abiertas, mas no necesariamente que ella haya instigado la acción de abrirlas. En 5 b, el sujeto no forzosamente causó el estado de internación del padre. Esta oración supone un vínculo afectivo entre el referente del sujeto y el objeto directo, por lo que el estado de este último afecta al primero. Por tanto, resulta dudosa la

\footnotetext{
${ }^{3}$ Para una descripción más detallada de los criterios de deslinde entre predicación secundaria y perífrasis, véase el trabajo de Sanz Martin (2011).
} 
gramaticalidad de una oración en la que no exista tal vínculo afectivo, como en 6 :

(6) ? Tengo internado al presidente de México en el hospital

Como vemos, en los ejemplos de 5, existe un vínculo entre el sujeto y el estado del objeto directo. En el primer caso, esto se debe a que el sujeto controla el estado del objeto directo, mientras que en el segundo, el sujeto se encuentra afectado por la situación estativa del objeto.

La idea de un estado vinculado con el sujeto se extiende a las construcciones perifrásticas, a pesar de que en estos casos no se predica el mantenimiento del estado del objeto directo, sino la instigación del proceso llevado a cabo por el sujeto (Sanz Martin, 2011).

El vínculo entre el estado y el sujeto se manifiesta en el hecho de que la perífrasis tener + participio es capaz de expresar la idea de relevancia en el presente, es decir, que un evento anterior produce efectos actuales en el sujeto. En estos contextos, no se predica el estado resultante en que se halla el referente del objeto directo, como se ilustró en 5, pero sí los efectos presentes en el sujeto de un evento pasado (Carey, 1996; Sanz Martin, 2011: 118-120). Por ejemplo, las oraciones de 7 refieren que un evento anterior trae como resultado un estado de conocimiento, de manera que aluden a la consideración detenida de algo o a la maduración de ideas o pensamientos (RAE, 2010: 28.16p), como se observa a continuación:

(7) a. Tengo pensado ir a tu casa

b. Ya lo tengo decidido 
Además del sentido perfectivo-resultativo y de relevancia en presente, la perífrasis tener + participio presenta otros significados vinculados con el aspecto verbal, como el valor perfectivo- acumulativo y el repetitivo o de insistencia.

Con respecto al primer valor, la perífrasis perfila el estado alcanzado que resulta de un proceso acumulativo, como se puede observar en los siguientes ejemplos extraídos de Gómez Torrego (1988: 192):

(8) a. Tengo escritos ya cincuenta folios, sólo me quedan veinte

b. Tengo empapeladas ya tres habitaciones, sólo me quedan la cocina y el baño

c. Tengo corregidos ya veinte exámenes, sólo me quedan diez

En otras ocasiones, la perífrasis expresa reiteración o insistencia en relación con lo que se dice o se hace (RAE, 2010: 28.16p, Gómez Torrego, 1988: 192), como en los siguientes ejemplos:

(9) a. Te tengo dicho que te calles

b. Te lo tengo advertido, luego no te quejes

Como hemos visto, el significado de la perífrasis tener + participio es básicamente aspectual, pues denota un proceso perfectivo que trae como consecuencia un resultado, lo que propicia otros significados aspectuales como el de relevancia en el presente, reiteración y acumulación. La idea de un estado resultante proviene de los matices estativos impuestos por el verbo tener. 


\section{Valores aspectuales del verbo entender}

Entender se puede clasificar desde el punto de vista léxico como un verbo de conocimiento, en tanto que supone una estructura con dos participantes: un ser consciente que lleva a cabo un proceso mental (experimentador) y una entidad abstracta producto del proceso llevado a cabo por el primer participante (fenómeno experimentado) (Halliday, 1985: 115-119).

El verbo en cuestión presenta múltiples acepciones: 'tener idea clara de las cosas', 'saber con perfección algo', 'conocer, penetrar', 'conocer el ánimo o la intención de alguien', 'discurrir, inferir, deducir,' 'tener intención o mostrar voluntad de hacer algo', 'creer, pensar, juzgar', 'tener amplio conocimiento y experiencia en una materia determinada, etcétera (RAE, 2001).

Todas las acepciones anteriores se pueden sintetizar en cuatro, las cuales fueron tomadas de la base de datos Alternancias de Diátesis y Esquemas Sintáctico-Semánticos del Español (ADESSE). A continuación se presenta cada una de las acepciones con un ejemplo representativo tomado de la misma base de datos mencionada:

1. Percibir [el sentido o significado de algo o de lo que alguien dice]. Comprender:

No entendimos nada de lo que decías

2. Tener conocimiento sobre [algo]. Saber:

No entiendo mucho de política ni de economía

3. Opinar o creer [algo] (sobre un asunto):

El Partido Popular entiende que esta partida presupuestaria es transitoria 
4. Tener trato o buena relación [alguien] [con alguien]:

¿Qué difícil entenderse con extraños si no es fácil comprender a los próximos!

En función de la acepción, el verbo entender presenta diferentes modos de acción (aktionsart). La aplicación de test gramaticales para discernir el aspecto léxico (cf. Vendler, 1967 y Dowty, 1979) muestra que en las acepciones 2 y 3 , el verbo se comporta como un verbo de estado, a diferencia de lo que ocurre con las acepciones 1 y 4 . Como se muestra en 10 , los sentidos de 'comprender' y 'tener trato o buena relación' aceptan la perífrasis progresiva, en cambio, cuando el verbo significa 'saber' u 'opinar o creer' resultan agramaticales:

(10) a. Estoy entendiendo las causas de la pobreza

b. ${ }^{\star}$ Estoy entendiendo de matemáticas

c. ${ }^{\star}$ Estoy entendiendo que las drogas no deben legalizarse

d. Me estoy entendiendo con Juan

La agramaticalidad de las acepciones 2 y 3, como se ilustra en $10 \mathrm{~b}$ y 10c, radica en que el verbo hace referencia a una experiencia cognoscitiva no dinámica y temporalmente ilimitada.

La dimensión no estativa de las acepciones 1 y 4 también se puede corroborar en el hecho de que estas aceptan la lectura en imperativo, como se ejemplifica en 11 :

(11) a. Entiéndelo

b. Entiéndete con tus hijos 
Entonces, si bien las acepciones 1 y 3 tienen en común que se refieren a situaciones no dinámicas, el modo de acción difiere en cada una de ellas. Cuando entender significa 'tener buena relación con alguien' su modo de acción es el de actividad, pues se refiere a una acción que se desarrolla durante un intervalo, y si se interrumpe en algún momento, puede decirse que la acción se ha dado. En cambio, cuando entender se refiere a 'comprender', se comporta como un verbo de logro, pues el proceso de percibir el significado o sentido de algo implica una acción que va dirigida a un objetivo, pero si la acción se ve interrumpida antes de llegar a él, no se ve realizada.

Para mostrar el contraste entre la actividad y el logro, se aduce la prueba sintáctica consistente en la colocación de las locuciones adverbiales por dos horas y en dos horas: la primera es adecuada para las actividades y la segunda lo es para las realizaciones (cf. Vendler, 1967 y Dowty, 1979). Aunque entender se comporta como un verbo de logro, la prueba sintáctica muestra cierta estructura interna en la que ocurren fases previas que conducen a la culminación del proceso indicada por el verbo. Obsérvense los siguientes ejemplos:

(12) a. Juan entendió la lección de matemáticas * por /en dos horas b. Juan se entendió con María por un año/ *en un año

Una vez expuestos los rasgos aspectuales del verbo entender, se procederá a analizar su comportamiento cuando aparece como núcleo perifrástico de tener + participio. 


\section{Valores aspectuales de tener entendido}

Como se había mencionado, la perífrasis tener + participio presenta un matiz aspectual perfectivo-resultativo impuesta por el auxiliar. Por ello, la perífrasis tener entendido expresa que, como resultado de un proceso cognitivo, el sujeto se encuentra en un estado resultante de cognición.

En este sentido, de acuerdo con los datos del corpus, existen restricciones léxicas para que el verbo entender figure como verbo nuclear de la perífrasis tener + participio. Me refiero a los casos en que el verbo en cuestión tiene la acepción de 'tener trato o buena relación'. Lo anterior sugiere una incompatibilidad del sentido habitual de la acepción con el aspecto perfectivo-resultativo de la perífrasis.

El verbo entender es compatible con la perífrasis en los contextos en que se expresa que, como resultado del proceso aludido por el participio, el sujeto se encuentra en un estado cognitivo resultante. De esta manera, se combinan los rasgos aspectuales de logro de entender con los matices estativos de tener.

El hecho de que el sujeto de la perífrasis tener entendido se halle en un estado cognitivo implica que el proceso de cognición debió llevarse a cabo íntegramente. Por ello, como veremos en el desarrollo de esta sección, las perífrasis tener entendido se caracterizan por un matiz completivo, ${ }^{4}$ de manera que se combina el significado de entender con los matices aspectuales impuestos por el auxiliar.

\footnotetext{
${ }^{4}$ En este trabajo se adopta la postura de Bybee, Perkings y Pagliuca (1994: 57), para quienes "working definition of completive is 'to do somethimg thoroughly and completely"”.
} 
En la acepción de 'comprender', en tanto verbo de logro, entender predica la culminación del proceso cognitivo. En los contextos perifrásticos, debido a los rasgos aspectuales del auxiliar, las oraciones expresan la idea de comprensión cabal y profunda de una entidad, por lo que presenta un sentido completivo, como se ilustra en 13:

(13) a. Celestina. Assí es; mas también, comadre, muchas vezes, haziendo bien se recibe mal. ZENARA. ¿Por qué dizes esso, comadre? Celestina. Tú me tienes entendida, y a buen entendedor pocas palabras, porque al sabio no es menester más de ponelle en el camino (Segunda Celestina, s. Xvi)

b. Es tan clara philosofía esa, que la tengo entendida yo muy bien (Viaje de Turquía, s. xvi)

En 13a, Zenara le pide a su interlocutora que le explique las palabras que acaba de proferir, a lo que Celestina se niega, en tanto que no es necesario explicar lo que su comadre ha comprendido perfectamente. Así, la oración me tienes entendida refiere a una comprensión total. Algo muy similar ocurre en 13b, donde el enunciador expresa que la claridad de la filosofía conduce a su comprensión total.

Como se aprecia en los ejemplos anteriores, el verbo entender presenta un matiz aspectual de logro, en tanto que existe la idea de la culminación de un proceso cognitivo, pero el auxiliar impone su significado estativo. Por ello, la perífrasis presenta una fusión conceptual o blend (cf. Fauconnier y Turner, 1996), de manera que emerge un significado de construcción (cf. Goldberg, 1995) en el que el auxiliar 
indica el estado mental en que se halla el sujeto tras la culminación del proceso al que alude el participio.

El verbo entender también aparece en la perífrasis cuando presenta el significado de 'tener conocimiento' sobre algo, como se observa en 14 , donde el hablante asegura tener conocimiento de lo que pueda decirle cierta persona.

(14) ¡Qué poca piedad tenéis! Elena. Escuchalde un rato os pido. Leonor. No tenéis que persuadirme, que cuanto puede decirme ya yo lo tengo entendido. Dirá que de amor perdido dos años ha que me adora, que me sirve y enamora, dando de mi olvido quejas a los hierros de mis rejas desde la noche a la aurora (El mayorazgo figura, s. XVII)

En el ejemplo anterior, se puede inferir del contexto que Leonor ha tenido experiencias previas con cierta persona que le ha declarado su amor, de manera que ella está familiarizada con su discurso. En este sentido, el verbo entender presenta un significado muy similar al de conocer, el cual, de acuerdo con Palancar (2000: 339), prototípicamente se refiere a "una situación en la cual un ser humano (el Sujeto) experimenta un tipo de actividad cognoscitiva que implica vivenciar cierta familiaridad (cognoscitiva) en relación con una entidad dada”. Según el autor, existen dos tipos principales de la experiencia cognitiva: 1) familiaridad simple, en la que el sujeto sabe simplemente un poco de la entidad, quizá solamente lo fundamental, como se plasma en 15a, y 2) familiaridad extensa, en la que el sujeto posee "un grado de conocimiento sobre una entidad dada que implica que 
está extensamente familiarizado con su ser o naturaleza" (2000: 340 ), como se ilustra en 15b:

(15) a. Conozco esa teoría (ejemplos tomados de Palancar 2000)

b. Conozco la estructura de la materia

El ejemplo 14 alude a una familiaridad extensa del hablante con el discurso amoroso, que proviene de su reiteración. El sujeto ha culminado el proceso de conocimiento de las palabras de amor del pretendiente y, como resultado de ese proceso cognitivo, se encuentra ampliamente familiarizado con ellas. Una vez más, se fusionan los rasgos semánticos de entender y tener. El primer verbo expresa el proceso cognitivo, en tanto que el segundo alude al estado resultante tras la culminación de dicho proceso. Además, la construcción mantiene los rasgos posesivos de tener, en el sentido de que el sujeto posee el conocimiento, es decir, el conocimiento se encuentra dentro de su dominio.

La idea de familiaridad extensa que surge de la fusión conceptual entre los verbos entender y tener puede también generar la idea de la posesión de un conocimiento íntegro, de manera que la construcción adquiere un matiz completivo, como se ejemplifica en 16 :

(16) Han de entrar en aquellas provincias con el gobernador y gente que llevare, religiosos de la orden de S. Francisco, porque ellos tienen entendida y paseada mucha parte de aquella tierra comarcana a la Nueva Galicia, y han bautizado y traído de paz muy gran cantidad de gente (Colección de documentos para la historia de México: versión actualizada, s. XIx) 
Obsérvese que el ejemplo que alude al amplio conocimiento de los religiosos de la orden de San Francisco de las tierras de Nueva Galicia. Así, la perífrasis expresa un proceso cognitivo total. Como resultado de tal proceso, el sujeto se encuentra en la posesión de un amplio conocimiento, es decir, el sujeto está extensamente familiarizado con la naturaleza de una entidad.

Tanto en la acepción de 'comprender' como la de 'tener conocimiento', la perífrasis tener entendido expresa un proceso cognoscitivo culminativo cuyo resultado es la posesión de conocimiento, el cual se ha adquirido cabal y exitosamente. De ese sentido completivo se desprende la lectura, en ciertos contextos, de la acepción de 'creencia'. Puesto que el hablante ha comprendido cabalmente una situación o está ampliamente familiarizado con ella, la tiene por cierta o verdadera. Se ilustrará lo anterior con la siguiente fábula de Samaniego:

(17) Fábula XXII. El Jabalí y la Zorra. Sus horribles colmillos aguzaba un Jabalí en el tronco de una encina. La Zorra, que vecina del animal cerdoso se miraba, le dice: -Extraño el verte, siendo tú en paz señor de la bellota, cuando ningún contrario te alborota, que tus armas afiles de esa suerte. La fiera le responde: - Tengo entendido que en la paz se prepara el buen guerrero, así como en la calma el marinero, y que vale por dos el prevenido (Fábulas, s. XVIII)

Por el contexto se puede inferir que el jabalí, a partir de un proceso de reflexión, comprende la importancia de prepararse para la guerra en época de paz y, como resultado del 
proceso de comprensión, obtiene un conocimiento exhaustivo. De esta manera, el sujeto está extensamente familiarizado con una situación específica. De esa familiaridad con la situación emana la convicción del jabalí de la importancia de la previsión. Con tengo entendido el enunciador expresa un alto grado de certeza ante el contenido referencial de la oración completiva. En este sentido, el verbo expresa una actitud proposicional, como pensar o creer. $^{5}$

En el ejemplo, el sujeto se encuentra en un estado cognitivo, la creencia en torno a la paz. Una vez más, este estado cognitivo es resultado de un proceso cognitivo que, en este caso, consiste en el proceso de reflexión. El verbo tener porta el rasgo de estativo de posesión de la creencia. El uso de entender de manera perifrástica y no como un verbo simple sugiere la idea de adquisición total del conocimiento y además se enfatiza la idea del estado mental en que se halla el sujeto.

Como hemos visto, tener entendido expresa la idea de un estado que resulta de un proceso cognitivo. En esta perífrasis, existe un significado de construcción, conformado por la noción de proceso del verbo nuclear y significado de estado del auxiliar. Asimismo, hemos observado que la perífrasis expresa la idea de proceso cognitivo completo y exhaustivo, por lo que presenta un matiz aspectual completivo.

\footnotetext{
${ }^{5}$ Por supuesto, el uso de tener entendido supone los matices aspectuales que se han abordado a lo largo del trabajo, por lo que no es totalmente equivalente a los verbos pensar y creer.
} 


\section{Modalidad epistémica en tener entendido}

Anteriormente se mencionó que en los contextos perifrásticos donde el verbo entender presenta la acepción de 'creencia', se predica que el sujeto, como resultado de un arduo proceso de reflexión, se encuentra ampliamente familiarizado con una situación específica y, en consecuencia, el enunciador expresa un alto grado de certeza con respecto a su aserción, por lo que la construcción expresa una actitud proposicional. Lo anterior se ilustró en 17.

Las construcciones que indican una actitud proposicional presentan una dimensión modal epistémica, pues indican el grado de certeza o duda que el emisor muestra con respecto a la verdad de la proposición contenida en su enunciado (Traugott, 1989; Bybee, Perkins y Pagliuca, 1994: 179-180).

En los contextos como el del ejemplo 17, aunque la perífrasis tiene una matiz modal, mantiene su contenido aspectual, pues aún persiste la idea de un proceso cognitivo que apunta a un resultado. En este sentido, los ejemplos de este tipo constituyen un contexto puente (cf. Heine, 2002) entre el aspecto y la modalidad de la perífrasis.

Ahora bien, en otros contextos, la perífrasis tener entendido puede rebasar el plano aspectual y presentar valores puramente modales epistémicos. Por ejemplo, en 18, la perífrasis expresa la noción de duda o poca certeza frente a la enunciación:

(18) a. verdes, salió a relucir, y el padre Cifuentes añadió que creía, tenía entendido, le parecía probable que la señora marquesa de Sabadell estaba a punto de salir (Pequeñeces, s. xIx) 
b. Tiene don Luis gran partido, y hará más, porque le ampara el conde de Trastamara, y, según tengo entendido, el prelado de Toledo (Macías, s. XIx)

El contexto adyacente a la forma perifrástica tengo entendido (creía y le parecía probable) en 18a muestra claramente poca certeza por parte del sujeto. En 18b, el hablante posee la certeza de que el conde de Trastamara ampara a don Luis, en cambio, únicamente presume el amparo del prelado de Toledo. De tener la certeza del amparo de ambos personajes, el hablante simplemente hubiese predicado le ampara el conde de Trastamara y el prelado de Toledo.

En otros contextos, la falta de certeza se manifiesta en el hecho de que el hablante verifica con el interlocutor la información, es decir, espera la respuesta del oyente para confirmar si su idea es acertada, tal como se ilustra en 19:

(19)a. Hoy justamente estoy muy amargado porque termino de escuchar el partido. Perdieron. Enc. - ¿Perdieron? Es muy bueno el equipo de San Lorenzo. Tengo entendido que hay un Fischer ahí que... Inf. - Ah sí. Anduvo muy bien el año pasado, pero no... no es una cosa que me preocupe, por otra parte (Habla Culta, Buenos Aires, s. xx)

b. Enc. - M., y tengo entendido que eres una mujer muy completa, que tienes... Inf.- ¡Oh, qué va! Enc.-...muchas aficiones interesantes [...] como, por ejemplo, la pintura. Cuéntanos. Inf.- Sí, eso sí (Habla Culta, Gran Canarias, s. xx)

c. Enc. - [...] Yo tengo entendido que tú viajaste a... a Alemania. Inf. - Sí. Sí estuve en el año, mil novecientos setentaiuno (Habla Culta, Lima, s. xx) 
Como se puede apreciar en los ejemplos, la construcción tener entendido denota que el sujeto posee una idea o creencia con respecto a un asunto. El hecho de que el hablante rectifique la información con el interlocutor pone en evidencia la idea de incertidumbre.

La diferencia entre los contextos puente, como en 17, con respecto a los contextos puramente modales radica en que los primeros expresan un compromiso epistémico del hablante, es decir, la idea de certeza; por el contrario, en los segundos, el hablante evita comprometerse con la veracidad de su afirmación. Así, hay un desarrollo semántico que va del valor de certidumbre hacia el de incertidumbre.

Esta transición de los significados aspectuales hacia los modales sugiere un mecanismo de cambio motivado por un proceso metafórico, en tanto que se presenta una extensión de un dominio más concreto a uno más abstracto (cf. Traugott, 1989; Bybee, Perkins y Pagliuca, 1994). Lo anterior obedece a que cuando la perífrasis tiene una dimensión aspectual, el verbo nuclear presenta los rasgos léxicos básicos del verbo entender ('comprender', 'tener conocimiento' o 'creer'). En cambio, en los contextos modales el verbo adquiere una significación más abstracta: la actitud del hablante frente a la certeza de su aserción.

Asimismo, la evolución del sentido aspectual al modal de la perífrasis tener entendido pone en evidencia un proceso de subjetivización (cf. Traugott, 1989: 37; 1995, Langacker, 1985, 1990, 1999), puesto que hay una transición de un significado más objetivo hacia uno subjetivo. Los contextos aspectuales, ciertamente, reflejan el mundo interno del hablante, en tanto que el verbo entender alude a sus creencias y 
estados cognitivos. Sin embargo, en los contextos modales, el significado de la perífrasis es aún más subjetivo, pues refleja una valoración o juicio por parte del hablante en torno a la certeza de sus afirmaciones.

Puesto que las perífrasis tener entendido con sentido modal expresan la actitud subjetiva del hablante, estas suelen aparecer conjugadas en primera persona del singular. De los 236 ejemplos documentados en los cinco siglos de perífrasis modales, únicamente 15 de ellos (el 6.3\%), presenta personas distintas a la primera de singular.

Por sí mismos, los verbos que expresan procesos mentales suelen ocurrir más frecuentemente en primera persona, pues suelen referirse al hablante con mucha mayor frecuencia que cualquiera de los otros tipos de proceso (Vázquez Rozas y García-Miguel, 2006: 14-15). ${ }^{6}$

Sin embargo, aún es más frecuente tal fenómeno cuando dichos verbos expresan modalidad epistémica, pues el hablante expresa una evaluación o punto de vista propio sobre el grado de certeza de su aserción, pero el cálculo del grado de certeza que perciben los demás resulta más difícil.

Además de que en los contextos modales las perífrasis expresan el grado de certeza de la aserción del hablante, en ciertos contextos, también se alude a las evidencias de la declaración, por lo que, como veremos en la siguiente sección, en las construcciones se manifiesta la categoría conocida como evidencialidad, recurso cuya función consiste en hacer

\footnotetext{
${ }^{6}$ Los autores citados ofrecen un minucioso análisis estadístico de los datos provenientes del corpus ARTHUS ("Archivo de Textos Hispánicos de la Universidad de Santiago"), que contiene datos de obras de diferentes géneros y una parte oral.
} 
una referencia a la fuente de información de la que dispone el hablante; es decir, al referir un hecho, el hablante señala si lo conoce de primera mano, ha oído de él, conjetura que fue así, etcétera, como señalan Chafe y Nichols, 1986; Aikhenvald, 2003, 2004; Nuyts, 2006; Willet, 1998, entre otros.

\section{El carácter evidencial de tener entendido}

En la sección anterior se ha aducido que la forma perifrástica adquiere un sentido modal epistémico. Ahora, se argumentará que de tal sentido modal emana un carácter evidencial.

Una de las grandes discusiones con respecto a la evidencialidad consiste en determinar si esta constituye un aspecto de la modalidad epistémica o si es un aspecto independiente de ella. Por ejemplo, Chafe y Nichols (1986) y Palmer (2001) consideran los evidenciales como marcadores de la actitud epistémica del hablante, pues la referencia a la fuente de la información constituye un medio para codificar el grado de confiabilidad de aquélla. Por ello, desde esta perspectiva, los significados evidenciales estarían englobados en el dominio de la modalidad epistémica. Por el contrario, otros autores (p. e. Aikhenvald, 2004; Fitneva, 2001; Plungian, 2001) consideran que no hay una relación entre el grado de seguridad (actitud del hablante, modalidad epistémica) y la fuente de información, en tanto que una misma fuente de información puede ser interpretada por hablantes diferentes con distintos grados de confiabilidad. Por nuestra parte, asumiremos la postura de que la evidencialidad pertenece al dominio de la modalidad epistémica. 
Partiremos de la propuesta de Palmer (2001:51), para quien la modalidad epistémica no sólo involucra las nociones de necesidad y posibilidad como en 20a y 20b, respectivamente, sino que engloba todos los sistemas modales que indiquen el grado de compromiso del hablante respecto de lo que dice.

(20) a. Ellos ya tienen que haber llegado porque salieron hace una hora

b. Puede ser que tengan frío

Palmer establece la distinción entre juicios - elementos que indican el grado de compromiso del hablante, pero que no involucran referencia a la fuente de información como 20 a y $20 \mathrm{~b}$, por ejemplo, y evidenciales, elementos que no únicamente indican el grado de compromiso del hablante, sino que además codifican la fuente de información, como ocurre en 21:

(21) De hoy más no quiero otro maestro, otro philósopho, ni más sabio consejero que a ti, para passar el discurso de la vida que me queda, y ruégote que no me dexes, que juntos passaremos aquí nuestra vida; que según tengo entendido por tu esperimentada narraçión es la mejor y más segura (El Crotalón, s. Xvi).

Como se puede apreciar, el sujeto de tengo entendido expresa la certeza de que la vida que comparte con su interlocutor es la mejor y más segura. La fuente de información o evidencia de tal aserción emana de la experimentada narración. 
El dominio de la evidencialidad presenta una organización interna, de manera que se pueden establecer dos grandes clases de evidencia: la directa y la indirecta. Esta distinción fue propuesta por Willet (1998: 57). De acuerdo con este autor, en la evidencia directa, el hablante obtiene la información por la vía sensorial, ya sea por medio de la vista, el oído u otros sentidos. ${ }^{7}$

En la indirecta, el hablante tiene acceso a la información por medio de un proceso de inferencia o deducción, o bien, a partir de la información recibida de terceros. Por ello, la evidencia indirecta puede ser referida o inferida.

El tipo de evidencia expresada por la perífrasis es la indirecta, tanto la referida como la inferida, como se puede apreciar en los ejemplos de 22:

(22) a. Y doña Clara de Toledo, marquesa de Palma, es el mejor mueble, o escalón, que podía proporcionarte la suerte. Mendoza: Y por eso me caso con ella. Además, tengo entendido que es una inocente, de carácter muy dulce, criada y educada en un convento de donde ha poco que salió. Mi tío es su tutor; me ha asegurado que no sabe qué cosas son galanteos, amigas, ni visitas, que no ve sino a él y al padre Rafael, confesor del rey y vicario de las

\footnotetext{
${ }^{7}$ Dentro de la categoría de evidencia directa, Tournade (1996, apud Bermudez, 2004: 6) añade la distinción entre evidencia sensorial y la evidencia endofórica. Esta última se refiere a una situación en la que el hablante describe entidades inaccesibles a los sentidos, como los deseos, la imaginación, las intenciones y los estados mentales en general, esto es, aquellas situaciones en los que la evidencia sensorial resulta imposible, pero en las que el hablante de todas maneras expresa evidencia directa.
} 
monjas con quienes se crió. ¡Cortada y hecha para mí! (Amor venga sus agravios, s. XIX)

b. esterilizaban a la gente del campo y sin que sepan que se estaban esterilizando. Enc. - ¿Tú sabes por qué hacían eso? [...] Inf.b. - No, no, era una... no sé qué sistema, me parece que era por el problema este justamente de la desnutrición y que había una mortalidad altísima en el altiplano. $\mathrm{O}$ sea mujeres que se llegan a embarazarse once, doce, trece, hasta catorce veces [...]. Y ellos querían que... que si han nacido dos niños, esos dos niños sean por lo menos bien... bien alimentados, por lo menos y no el resto que eran gente enferma, desnutrida, incluso morían; o sea, para evitar la mortalidad, diríamos. Ese era el fin de ellos, o sea, para ayudar... ese tipo de ayuda creían prestar. Es lo que yo tengo entendido, mirá [sic], no sé exactamente el programa mismo, pero te digo lo que más o menos sé así de refilón (Habla Culta, La Paz, s. xx).

c. Enc.- ¿Ah, tiene escuela? Inf. - Sí, para iniciar los niños. Ella es como que... tengo entendido, me han dicho que es muy buena profesora (Habla Culta, México, s. xx).

En 22a, Mendoza sabe de la inocencia, dulzura y recato de Doña Clara de Toledo a través de su tío. En 22b, el hablante infiere que para evitar el alto índice de embarazos, mejorar la calidad de vida y disminuir la tasa de mortandad, se creó un programa de esterilización. En 22c, el hablante realiza una aseveración, cuya fuente de información proviene de lo que han dicho otras personas.

Los datos del corpus arrojan la existencia de ciertos contextos puente (cf. Heine, 2002) que permiten que haya 
una transición de los significados resultativos hacia los modales epistémicos de tipo evidencial. Estos casos aluden a que, como resultado de un proceso cognitivo, el sujeto se encuentra en un estado de conocimiento o creencia, pero además se especifica que hubo una entidad o circunstancia que causó dicho proceso. En otras palabras, los ejemplos expresan que debido a lo que alguien dice o a partir de ciertos indicios que permiten hacer una inferencia, el sujeto conoce o cree algo, como ocurre en 23 :

(23) a. En el capítulo cuarenta y siete, hablando de aquellas provincias, dice lo que se sigue: "Volviendo, pues a[1] propósito digo que (según yo tengo entendido de indios viejos, capitanes que fueron de Guaina Capa) que en tiempo del gran Topa Inga Yupangue vinieron ciertos capitanes" (Comentarios reales, $\mathrm{s} . \mathrm{XVI}$ )

b. Y porque esto es claro y manifiesto a todos los que habemos visto la fertilidad de la tierra, y abundancia de las cosas, para la sustentación de los hombres pertenecientes; y porque desta línea equinoccial se toca en algunas partes desta historia, por tanto daré aquí razón de lo que della tengo entendido de hombres peritos en la cosmografía; lo cual es, que la línea equinoccial es una vara o círculo imaginado por medio del mundo (Crónica del Perú, s. $\mathrm{XVI}$ )

c. Pero esfuérçome a te la pintar [a ti, Miçilo,] lo más en la verdad que puedo, porque tengo entendido de tu cordura que con tu buen crédito debajo destas toscas y cortas palabras entenderás lo mucho que quiero significar (Diálogo de Mercurio y Carón, s. Xvi) 
d. Miçilo, ven acá; mira que me hagas una graçia, un soberano serviçio y plazer. Haslo de hazer con buena voluntad, porque tengo entendido de tu buena diligençia y buena inclinaçión que a ti sólo puedo encomendar una cosa que yo tanto amo, y de ti sólo se puede fiar (Diálogo de Mercurio y Carón, s. XvI)

En los dos primeros ejemplos, el sujeto se encuentra en un estado cognitivo debido a la fuente de información reportada por los indios viejos en 23a y por los hombres peritos en cosmografía en $23 \mathrm{~b}$. Por otro lado, los ejemplos de 23 c y $23 d$ expresan que el sujeto se halla en un estado cognitivo debido a un proceso de inferencia. En 23c, el hablante infiere que, debido a la cordura del oyente, este entenderá las palabras de aquel. En 23d, la diligencia y buena inclinación del interlocutor le permiten inferir al sujeto que puede encomendarle la cosa que tanto ama.

Estos contextos sugieren que el sentido evidencial de la perífrasis resulta de un mecanismo de cambio semántico por inferencia (cf. Bybee, Perkins y Pagliuca, 1994), que consiste en lo siguiente: el sujeto no explicita el origen de un estado cognitivo, es decir, la fuente de información referida o inferida, pero el oyente es capaz de inferirla. Al paso del tiempo, los significados evidenciales se convencionalizan, pues como se mencionó en la introducción, que presenta un análisis cuantitativo, en el siglo xx casi todos los ejemplos registrados de la perífrasis tener entendido poseen una dimensión epistémica y esta es, en la mayoría de los casos, de tipo evidencial. 
Cabe señalar que el desarrollo del sentido aspectual hacia el evidencial por un proceso de inferencia es una ruta tipológica común. Según Bybee, Perkins y Pagliuca (1994: 95-96), los evidenciales, al igual que los resultativos, describen una acción pasada, pero los segundos además añaden que tal acción es conocida por los efectos presentes, es decir, la inferencia se basa en los resultados. Por ejemplo, si en inglés se predica Mary is gone, se puede inferir que el sujeto se ha ido porque está ausente. Ahora bien, el componente evidencial se puede generalizar al grado de hacer una inferencia a partir de un razonamiento (sin resultados directos) o a partir de una evidencia reportada (1994: 97), tal como ocurre en la perífrasis tener entendido.

\section{Conclusiones}

La perífrasis tener + participio aporta un significado esencialmente aspectual, ya que predica la culminación de un proceso alcanzado. No obstante, en el desarrollo del trabajo se comprobó que en los contextos donde el verbo nuclear de la perífrasis es entender, la perífrasis puede revestirse de un valor modal, en tanto que la actitud del hablante frente a lo dicho pasa a formar parte del significado de la construcción.

Una de las aportaciones de este trabajo consiste en demostrar que en la construcción tener entendido existe una evolución progresiva que va del aspecto hacia la modalidad, es decir, diacrónicamente los sentidos modales van desplazando a los aspectuales. 
Para comprender el proceso evolutivo hacia la modalidad, el trabajo describió la dimensión aspectual de la perífrasis tener entendido, la cual consiste en la expresión de un estado cognitivo resultante de un proceso cabal. Se argumentó que la perífrasis es resultado de un significado de construcción en el que intervienen los rasgos aspectuales de proceso de entender y los rasgos estativos y posesivos de tener.

Posteriormente, se describieron los contextos en los cuales la perífrasis presenta una modalidad de tipo epistémico, los cuales se caracterizan por expresar la actitud epistémica del hablante; es decir, el grado de certeza que muestra ante el contenido de la proposición.

Por otro lado, se mostró que de los sentidos modales epistémicos de la perífrasis surge una dimensión evidencial, a partir de la cual se expresa que la fuente de información de la aserción del hablante proviene de la inferencia o lo referido por otras personas (evidencia indirecta). Al respecto, se adujo que la evolución del sentido resultativo hacia la evidencialidad es congruente con una ruta diacrónica y tipológica observada frecuentemente en las lenguas del mundo.

La evolución del aspecto hacia la modalidad ofreció evidencia a favor de ciertas tendencias del cambio gramatical, como la subjetivización, los procesos metafóricos, los procesos de inferencia y la convencionalización.

Asimismo, se mostró que en la ruta evolutiva que va de la aspectualidad hacia la modalidad existen contextos puente, en donde se combinan tanto los rasgos aspectuales como los modales. De ahí, surgen contextos en donde los 
significados modales desplazan por completo a los aspectuales, como se ilustra a partir del siguiente diagrama:

\section{CONTEXTOS PUENTE}

$\begin{aligned} & \text { significado } \longrightarrow \text { significado } \\ & \text { aspectual }\end{aligned}+\begin{aligned} & \text { significado } \longrightarrow \text { significado } \\ & \text { modal }\end{aligned} \underset{\text { modal }}{\longrightarrow}$

Los contextos puente dan origen a dos significaciones modales básicas: la noción de compromiso epistémico del hablante y la evidencialidad.

Los contextos puente de donde emana el significado vinculado al compromiso epistémico del hablante consisten en lo siguiente: se expresa el rasgo aspectual de conocimiento o comprensión cabal, es decir, el rasgo aspectual completivo, lo que genera la idea de certeza. En los contextos puramente modales, se observa un desplazamiento de la expresión de certeza hacia la idea de incertidumbre, como se ilustra a continuación:

\section{CONTEXTO PUENTE}

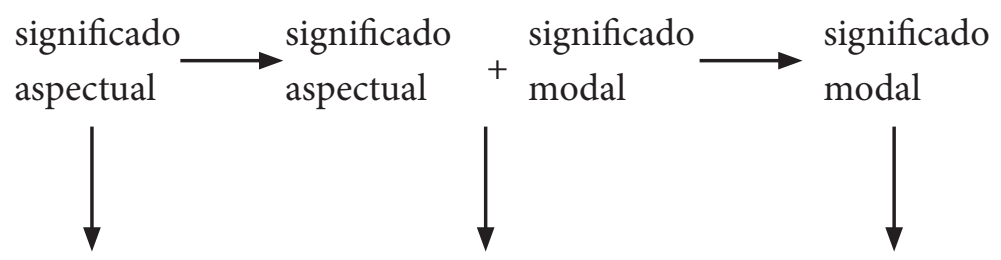

completivo

$\rightarrow$ completivo + 'certeza' (actitud epistémica)

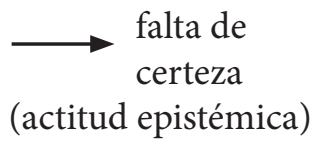


Por otro lado, los matices evidenciales surgen de los contextos que expresan que el resultado de un proceso cognoscitivo cabal (aspecto completivo) fue originado por la evidencia inferida o referida, es decir, el sujeto se halla en un estado cognoscitivo debido a lo que ha inferido o escuchado de otras personas. De ahí, surgen los contextos en donde no se hace explícita la evidencia referida o inferida, pero esta se puede recuperar mediante un proceso de inferencia, que posteriormente se convencionaliza. La esquematización de la ruta evolutiva sería la siguiente:

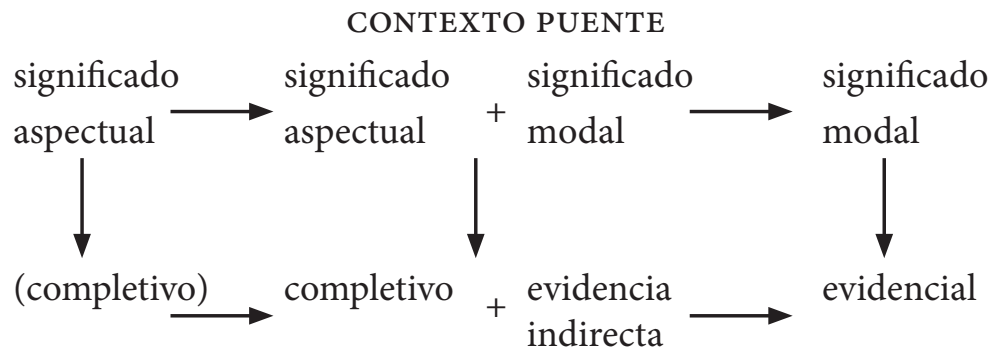

En suma, en este trabajo se describieron los mecanismos de cambio involucrados en el desplazamiento del aspecto por la modalidad epistémica presentes en la construcción perifrástica tener entendido.

\section{Corpus}

DAVIES, MARK. Corpus del español (100 millones de palabras, siglo XIII-siglo Xx, en construcción desde el año 2002). Disponible en $<$ http://www.corpusdelespanol.org $>$. 
Universidad de Vigo. Base de datos de Verbos, Alternancias de Diátesis y Esquemas Sintáctico-Semánticos del Español (ADESSE). Disponible en $<$ http://adesse. uvigo.es/>

\section{Bibliografía}

Aikhenvald, A. (2003), "Evidentiality in typological perspective", en A. Aikhenvald, Alexandra y R. M. W Dixon (eds.), Studies in Evidentiality, Filadelfia, John Benjamins, pp. 1-31.

- (2004), Evidentiality, Oxford, Oxford University Press.

Bermúdez, F. (2004), "La categoría evidencial del castellano: metonimia y elevación del sujeto", Boletín de Lingüística, 22, pp. 3-31.

Bybee, J. L., R. Perkins y W. Pagliuca (1994), The evolution of grammar: Tense, aspect and modality in the languages of the world, Chicago-Londres, The University Chicago Press.

Carey, K. (1996), "From Resultativity to Current Relevance Evidence from the History on English and Modern Castilian Spanish", en A. Goldberg (ed.), Conceptual Structure, Discourse and Language, Stanford: CSLI Publications.

Castillo, D. D. (2002), "La carta privada como práctica discursiva: Algunos rasgos característicos", Signos, 35(51-52), pp. 33-57. Recuperado en 01 de diciembre de 2013, de http://www. scielo.cl/scielo.php?script=sci_arttext\&pid=S0718- 
09342002005100003\&lng=es\&tlng=es. 10.4067/S071809342002005100003.

Chafe, W. y J. Nichols (1986), "Evidentiality in English conversation and Academic Writing", en Evidentiality in Linguistic Coding of Epistemology, Norwood, Nueva Jersey, Ablex Publishing Corporation.

Dowty, D. R. (1979), Word Meaning and Montague Grammar: The Semantics of Verbs and Times in Generative Semantics and in Montague's PTQ, Dordrecht, D. Reidel. Fauconnier, G. y M. Turner (1996), "Blending as a central process of gramar", en A. Goldberg (ed.), Conceptual Structure, Discourse, and Language, Stanford: CSLI Publications, pp. 113-130.

Fitneva, S. (2001), "Epistemic markers and reliability judgments: Evidence from Bulgarian", Journal of Pragmatics, 33, pp. 401-420.

Goldberg, A. E. (1995), Constructions: A Construction Grammar Approach to Argument Structure, Chicago, University of Chicago Press.

Gómez Torrego, L. (1988), Perifrasis verbales: sintaxis, semántica y estilística, Madrid, Arco Libros.

Halliday, M. A. K. (1985), An Introduction to Functional Grammar, Londres, Arnold.

Heine, B. (2002), "On the role of context in grammaticalization", en I. Wischer y G. Diewald (eds.), New reflections on grammaticalization, Ámsterdam, John Benjamins (Typological Studies in Language 49).

LANGACKER, R. W. (1985), "Observations and speculations on subjectivity", en J. Haiman (ed.), Iconicity in syntax, Ámsterdam, John Benjamins, pp. 109-150. 
LANGaCKer, R. W. (1990), “Subjectification”, Cognitive Linguistics, 1, pp. 5-38.

- (1999), "Losing control: Grammaticization, subjectification and transparency", en A. Blank y P. Koch (eds.), Historical semantics and cognition, Berlín / Nueva York, Mouton de Gruyter, pp. 147-176.

Nuyts, J. (2006), "Modality: overview and linguistic issues", en E. Eschenroeder, S. Mills y T. Nguyen (eds.), The Expression of Modality, Berlín / Nueva York, Mounton de Gruyter.

Palancar, E. (2000), "Del verbo conocer en español: un estudio morfodinámico del aspecto léxico", Revista Española de Lingüística Aplicada, volumen monográfico, pp. 339-354.

Palmer, F. R. (2001), Mood and Modality, 2a ed., Cambridge, Cambridge University Press.

Plungian, V. (2001), "The place of evidentiality within the universal grammatical space", Journal of Pragmatics, 33, pp. 349-357.

Real Academia Española (2010), Nueva gramática de la lengua Española, Madrid, Espasa Calpe.

- (2001), Diccionario de la lengua española, 22a ed., Madrid, Espasa Calpe.

SAnz Martin, B. E. (2011), El proceso de auxiliarización del verbo tener. De la posesión al aspecto, Aguascalientes, Universidad Autónoma de Aguascalientes.

Tournade, N. (1996), "Comparaison des systèmes médiatifs de quatre dialectes tibétains (tibétain central, ladakhi, dzonkha et amdo)", en Z. Guentchéva (ed.), Lentonation médiatisée, París, Peeters, pp. 195-213. 
Traugott, E. C. (1989), "On the rise of epistemic meaning in English: an example of subjetivization in semantic change", Language, 65, 1, pp. 31-55.

- (1995), "Subjetification in grammaticalization", en D. Stein y S. Wrigth (eds.), Subjetivity and subjetivisation. Linguistic Perspectives, Cambridge, Cambridge University Press, pp. 31-54.

- (2005), "Historical aspects of modality", en E. Eschenroeder, S. Mills y T. Nguyen (eds.), The Expression of Modality, Berlín / Nueva York, Mouton de Gruyter, pp. 107-140.

Vázquez Rozas, V. y J. M. García-Miguel (2006), “Transitividad, subjetividad y frecuencia de uso", VII Congrés de Lingüística General, Barcelona, 18 al 21 de abril de 2006 [Actas en CD-ROM. ISBN: 84-475-2086-8]. Disponible en: http://webs.uvigo.es/a575/jmgm/public/ VazquezRozas-GarciaMiguel_CLG7.pdf

Vendler, Z. (1967), "Verbs and times", en Z. Vendler (ed.), Linguistics in Philosophy, Nueva York, Cornell University Press, pp. 97-121.

Willet, T. (1998), "A cross-linguistics survey of the grammaticalization of evidentiality", Studies in Language, 12, pp. 57-91.

Yllera, A. (1999), "Las perífrasis verbales de gerundio y participio", en I. Bosque y V. Demonte (eds.), Gramática descriptiva de la lengua española, vol. 2. Las construcciones sintácticas fundamentales. Relaciones temporales, aspectuales y modales, Madrid, Espasa Calpe, pp. 3391-3442. 
